\title{
Functional and structural properties of CbpA, a collagen-binding protein from Arcanobacterium pyogenes
}

\section{Correspondence \\ P. Speziale \\ pspeziale@unipv.it}

Received 24 April 2007

Revised 26 June 2007

Accepted 26 June 2007

\author{
Giampiero Pietrocola, ${ }^{1}$ Viviana Valtulina, ${ }^{1}$ Simonetta Rindi, ${ }^{1}$ B. Helen Jost ${ }^{2}$ \\ and Pietro Speziale ${ }^{1}$ \\ ${ }^{1}$ University of Pavia, Department of Biochemistry, Viale Taramelli 3/B, 27100 Pavia, Italy \\ ${ }^{2}$ Department of Veterinary Science and Microbiology, The University of Arizona, Tucson, AZ 85721 , \\ USA
}

\begin{abstract}
Arcanobacterium pyogenes, an opportunistic pathogen of economically important food animals, is the causative agent of liver abscesses in feedlot cattle, osteomyelitis in turkeys, and pneumonia and arthritis in pigs. Previous studies identified the first $A$. pyogenes adhesin, CbpA, a protein located on the bacterial surface which has the ability to bind collagen and promotes adhesion to the host cells. The protein has an $\mathrm{N}$-terminal ligand-binding region (region $\mathrm{A}$ ) and a $\mathrm{C}$-terminal repetitive domain (region $\mathrm{B}$ ). In this study we found that $\mathrm{CbpA}$ bound to almost all the collagen types tested but not to other proteins, and it displayed a propensity to interact with several collagenous peptides derived by CNBr cleavage of type I and II collagens. The $K_{\mathrm{D}}$ values of $\mathrm{CbpA}$ for type I and II collagens and collagen peptides determined by solid-phase binding assay and intrinsic tryptophan fluorescence were in the range of 1-15 $\mathrm{nM}$. It was also found that $\mathrm{CbpA}$ and its $A$ region bound fibronectin, and that collagen and fibronectin interacted with distinct subsites. Anti-CbpA antibodies were effective at inhibiting both binding of isolated CbpA and bacterial adhesion to immobilized collagen, suggesting that $\mathrm{CbpA}$ is a functional collagen-binding adhesin. Analysis of the immunological cross-reactivity of $\mathrm{CbpA}$ with antibodies against other bacterial collagen-binding proteins indicated that $\mathrm{CbpA}$ is immunologically related to ACE from Enterococcus faecalis but not to CNA from Staphylococcus aureus or Acm from Enterococcus faecium. Far-UV and near-UV circular dichroism spectra showed that full-length CbpA and its region $\mathrm{A}$ are mainly composed of $\beta$-sheet with only a minor $\alpha$-helical component and that both the proteins have a well-defined tertiary structure.
\end{abstract}

\section{INTRODUCTION}

Arcanobacterium pyogenes is a ubiquitous inhabitant of the mucous membranes of cattle, swine and many other animal species (Jost \& Billington, 2005). As an opportunistic pathogen, A. pyogenes can cause a variety of suppurative diseases in animals compromised by previous microbial infection or trauma. Economically significant disease includes liver abscessation in beef cattle, and pneumonia and arthritis in swine (Jost \& Billington, 2005). A. pyogenes is armed with several factors that contribute to its pathogenesis, including a cholesterol-dependent cytolysin, pyolysin (Billington et al., 1997), several proteases (Schaufuss et al., 1989) and a number of adhesive mechanisms, including two cell-surface neuraminidases (Jost et al.,

Abbreviations: $\mathrm{CB}$ peptide, collagen fragment generated by $\mathrm{CNBr}$ cleavage; $\mathrm{CD}$, circular dichroism; ECM, extracellular matrix; ITF, intrinsic tryptophan fluorescence; MSCRAMM, microbial surface component recognizing adhesive matrix molecules.
2002) and a collagen-binding protein, CbpA (Esmay et al., 2003).

Adhesion to the host is an important first step in bacterial colonization and disease pathogenesis. Bacteria target a wide variety of host molecules, but a common mechanism used by a number of pathogens is binding to components of the host extracellular matrix (ECM). In Gram-positive organisms, ECM binding is almost exclusively the property of a number of bacterial surface proteins designated microbial surface components recognizing adhesive matrix molecules (MSCRAMMs) (Foster \& Höök, 1998). CbpA is a $121.9 \mathrm{kDa}$, surface-expressed protein that binds type I collagen, and is involved in mediating adherence to epithelial and fibroblast cell lines (Esmay et al., 2003). As reported for other MSCRAMMs (Foster \& Höök, 1998), CbpA has a modular domain structure consisting of an $\mathrm{N}$ terminal signal peptide, a non-repetitive A region, and four repeated units (B region), followed by a cell-wall anchor region, a transmembrane segment, and a short positively 
charged cytoplasmic tail. In addition, this protein has amino acid similarity to the collagen-binding adhesin CNA of Staphylococcus aureus.

A number of studies have directly linked collagen-binding MSCRAMMs to disease processes in collagen-rich tissues. Staph. aureus CNA has been demonstrated as a virulence factor in several experimental animal models, including colonization of the joints in mice (Xu et al., 2004a). Similarly, ACE, the collagen adhesin of Enterococcus faecalis, is important for adherence to dentin in tooth root canals (Hubble et al., 2003). The crtical role of the bacterial attachment to collagen is further indicated by identification of collagen-binding proteins in a variety of micro-organisms such as M3 protein from Streptococcus pyogenes (Dinkla et al., 2003), protein FOG in Streptococcus dysgalactiae equisimilis (Nitsche et al., 2006), YadA of enteropathogenic Yersinia species (Nummelin et al., 2004) and CbsA from Lactobacillus crispatus (Antikainen et al., 2002).

CbpA is present in $48 \%$ of $A$. pyogenes isolates; however, $100 \%$ of turkey osteomyelitis isolates were $c b p A^{+}$(Esmay et al., 2003), possibly implicating CbpA in the pathogenesis of osteomyelitis.

This study further extends the biochemical analysis of A. pyogenes $\mathrm{CbpA}$ with respect to its binding properties for collagens, as well as to structure and immunological correlations with other bacterial collagen-binding proteins.

\section{METHODS}

Proteins. Mouse laminin was purchased from BD Biosciences; BSA, ovalbumin and human type III, IV and V collagens were from Sigma. Human fibrinogen (Calbiochem) was made free of contaminating fibronectin by purification over a gelatin-Sepharose column. Fibronectin was purified from human plasma as previously reported (Vuento \& Vaheri, 1979). Recombinant Acm was a generous gift from Dr B. E. Murray (University of Texas Medical School, Houston, TX, USA). CNA19 (residues 151-319), and ACE40 (residues 32-367) were kindly provided by $\mathrm{Dr}$ M. Höök (Texas A\&M University Health Science Center, Houston, TX, USA).

Collagens and CB peptides. Type I collagen from calf skin was a gift from Dr R. Tenni (Dept of Biochemistry, University of Pavia, Italy). CB peptides were obtained by cleavage of type I collagen with $\mathrm{CNBr}$ and purified by gel-filtration chromatography followed by ionexchange chromatography (Rossi et al., 1996). Type II, IX and XI collagens were purified from bovine nasal septum (Reese \& Mayne, 1981). Type II collagen CNBr peptides were isolated essentially following the procedures used for peptides from type I collagen (Rossi et al., 1996). All collagens and peptides were analysed for purity by a quantitative Hyp assay (Huszar et al., 1980), by electrophoresis in denaturing conditions (Laemmli, 1970), and by N-terminal sequencing for some peptides, and for conformation by means of circular dichroism spectroscopy.

Expression and purification of CbpA proteins. Cloning of recombinant CbpA, lacking the signal peptide (residues 28-1151), and the A domain of CbpA (residues 29-355) was performed as reported previously (Esmay et al., 2003).
The fusion proteins, containing an $\mathrm{N}$-terminal His-tag, were purified by immobilized metal chelate affinity chromatography and gel filtration chromatography on a Superose $12 \mathrm{HR}$ column fitted on an FPLC system. The purity of the isolated proteins was assessed by SDS-PAGE.

Bacteria and growth conditions. Escherichia coli DH $5 \alpha \mathrm{MCR}$ harbouring plasmid pJGS591 (Esmay et al., 2003) was routinely grown in Luria broth or in Luria agar (Difco) containing $100 \mu \mathrm{g}$ ampicillin $\mathrm{ml}^{-1}$ at $37^{\circ} \mathrm{C}$. Enterococcus faecium 395 cultures were grown in Brain Heart Infusion (BHI; Difco) at $37^{\circ} \mathrm{C}$. Enterococcus faecalis 706897 was grown in $\mathrm{BHI}$ medium at $46{ }^{\circ} \mathrm{C}$. A. pyogenes BBR1 was grown in BHI supplemented with $5 \%(\mathrm{w} / \mathrm{v})$ newborn calf serum and $5 \mu \mathrm{g}$ tetracycline $\mathrm{ml}^{-1}$ at $37^{\circ} \mathrm{C}$.

Biotin labelling of CbpA. CbpA ( $0.5 \mathrm{mg})$ dissolved in $0.5 \mathrm{ml}$ PBS, $\mathrm{pH} 7.4$, was mixed with $0.5 \mathrm{ml} 0.2 \mathrm{M}$ sodium borate buffer, $\mathrm{pH} 8.0$, and $7.5 \mathrm{mg} \quad \mathrm{N}$-hydroxysuccinimidobiotin (NHS-biotin) (Sigma) dissolved in $0.1 \mathrm{ml} \mathrm{DMSO}$, and incubated at $22{ }^{\circ} \mathrm{C}$ overnight with end-over-end mixing. The labelling mixture was dialysed against PBS and stored at $-20{ }^{\circ} \mathrm{C}$ in small aliquots.

Polyclonal and monoclonal antibodies. Antibodies to recombinant CbpA, ACE40, CNA19 and Acm were raised in BALB/c mice. Injections were given intraperitoneally four times at 1 week intervals with $50 \mu \mathrm{g}$ of the antigen emulsified with an equal volume of complete Freund's adjuvant for the first immunization, followed by three injections in Freund's incomplete adjuvant. The mice were bled and the sera were tested for reactivity against the corresponding antigen.

The mAbs against ACE40 and CNA19 were produced essentially as described by Köhler \& Milstein (1975) with minor modifications. Hybridoma supernatants were screened for reactivity with the appropriate antigen immobilized on microtitre plates and positive clones were further characterized by ELISA and Western blotting.

Antibodies from the sera and hybridoma supernatants were purified by affinity chromatography on protein G-Sepharose according to the recommendations of the manufacturer (Amersham Biosciences). Isotyping of the mAbs produced was performed using a Mouse-Typer subisotyping kit (Bio-Rad). All the mAbs were found to belong to the IgG isotype.

ELISA. The binding of CbpA proteins to plasma or ECM proteins was determined in an ELISA-type assay. Unless otherwise stated, microtitre wells were coated with $100 \mu \mathrm{l}$ of $10 \mu \mathrm{g} \mathrm{ml}^{-1}$ of the indicated proteins dissolved in $50 \mathrm{mM}$ sodium carbonate, $\mathrm{pH}$ 9.5. To block additional protein-binding sites, the wells were treated for $1 \mathrm{~h}$ with $200 \mu \mathrm{l} 2 \%(\mathrm{w} / \mathrm{v}) \mathrm{BSA}$ in PBS at $22{ }^{\circ} \mathrm{C}$. The wells were then washed with PBST (PBS $+0.5 \%, v / v$, Tween 20 ) and incubated for $1 \mathrm{~h}$ with $1 \mu \mathrm{g} \mathrm{CbpA}$ or region A of CbpA. After washing, bound ligand was incubated for $1 \mathrm{~h}$ with $1 \mu \mathrm{g}$ mouse anti-CbpA IgG followed by $1 \mathrm{~h}$ incubation with peroxidase-conjugated rabbit antimouse IgG (Dako). The conjugated enzyme was allowed to react with $o$-phenylendiamine dihydrochloride (Sigma) and absorbance at $490 \mathrm{~nm}$ was measured using a microplate reader (Bio-Rad). To calculate the relative association constant $\left(K_{\mathrm{a}}\right)$ values of CbpA proteins for type I and II collagens and collagen peptides from the saturation kinetics, the following equation was used: $A=A_{\max }[\mathrm{CbpA}] K_{\mathrm{a}} /\left(1+K_{\mathrm{a}}[\mathrm{CbpA}]\right)$.

The reported $K_{\mathrm{D}}$ values were calculated as the reciprocal of the corresponding association constants.

To measure the adsorption of each protein to the plates, protein bound to the wells was determined by using a BCA protein assay kit, Microplate Procedure, Protocol \#2161297A (Pierce): in these conditions, a $80-90 \%$ coating efficiency was detected for each protein tested. 
The binding of CbpA to collagen in the presence of anti-CbpA antibodies was studied by incubating collagen-coated microtitre plates $\left(1 \mu \mathrm{g}\right.$ per well) with $1 \mu \mathrm{g}$ biotin-labelled CpbA for $1 \mathrm{~h}$ at $22{ }^{\circ} \mathrm{C}$. CbpA bound to collagen was detected by the addition of a $1: 2000$ dilution of avidin-peroxidase followed by a chromogenic substrate, and absorbance at $490 \mathrm{~nm}$ was measured using a microplate reader.

Attachment of A. pyogenes cells to collagen-coated wells was performed by incubating microtitre plates coated with collagen type I $\left(1 \mu \mathrm{g}\right.$ per well) with $5 \times 10^{7}$ bacterial cells for $90 \mathrm{~min}$. After three washes, collagen-bound bacteria were incubated with $1 \mu \mathrm{g}$ of a rabbit anti-A. pyogenes IgG. Binding of antibody to bacteria was detected by addition of a peroxidase-labelled goat anti-rabbit secondary antibody.

Immunological reactivity of collagen-binding proteins. Crossreactivity of recombinant adhesins from A. pyogenes (CbpA), Staph. aureus (CNA), Ent. faecalis (ACE) and Ent. faecium (Acm) was analysed by incubating adhesin-coated microtitre wells ( $1 \mu \mathrm{g}$ per well) with $1 \mu \mathrm{g}$ mouse IgG isolated from immune sera against each adhesin or with $1 \mu \mathrm{g}$ of individual mouse monoclonal antibodies raised against ACE40. Binding of the antibodies to the wells was detected by addition of $1 \mu \mathrm{g}$ peroxidase-conjugated rabbit anti-mouse antibody.

Immunological reactivity of bacterial species expressing collagen-binding proteins. Microtitre wells were coated with $100 \mu \mathrm{l}$ of bacterial cells $\left(5 \times 10^{7}\right.$ per well $)$ in PBS, overnight at $37{ }^{\circ} \mathrm{C}$. After incubating with $2 \%(\mathrm{w} / \mathrm{v})$ BSA the bacteria-coated wells were washed with PBST and incubated for 90 min with $1 \mu \mathrm{g}$ IgG of individual monoclonal antibodies against CNA19 or ACE40. The wells were washed three times and incubated with $1: 1000$ dilution of peroxidase-conjugated rabbit anti-mouse antibody. The conjugated enzyme was allowed to react with $o$-phenylendiamine dihydrochloride and absorbance at $490 \mathrm{~nm}$ was measured using a microplate reader.

Circular dichroism (CD) spectroscopy. Far-UV (195-250 nm) and near-UV (250-320 nm) CD measurements were performed at $20{ }^{\circ} \mathrm{C}$ in 0.1 and $1.0 \mathrm{~cm}$ pathlength quartz cuvettes, respectively. CD spectra were recorded on a Jasco J-720 spectropolarimeter. The results are expressed as the mean residue ellipticity assuming a mean residue weight of 110 amino acid residues. All the spectroscopic measurements were performed in $20 \mathrm{mM}$ phosphate buffer $\mathrm{pH}$ 7.4. Six scans were averaged for each spectrum, and the contribution from the buffer was subtracted in each case. Quantification of secondary structural components was performed using the deconvolution programs CONTIN, CDSSTR and SELCON3.

Intrinsic tryptophan fluorescence. The intrinsic tryptophan fluorescence of $0.2 \mu \mathrm{M}$ CbpA proteins in PBS was examined with a Jasco FP-6500 spectrofluorimeter at $22{ }^{\circ} \mathrm{C}$. The excitation wavelength was set at $295 \mathrm{~nm}$ (5 nm slit width) while monitoring emission from 305 to $400 \mathrm{~nm}$ (5 nm slit width). Quenching of tryptophan fluorescence after the addition of collagen (from 0.0015 to $0.1 \mu \mathrm{M}$ ) was analysed via a modified Stern-Volmer plot (Eftink \& Ghiron, 1981 ) as follows. The $F_{0} /\left(F_{0}-F\right)$ ratio (where $F_{0}$ and $F$ are the fluorescence intensities at $338 \mathrm{~nm}$ in the absence and presence of collagen, respectively) plotted against the reciprocal of CbpA concentration yields a straight line, the intercept of which on the $x$ axis equals the value of the association constant $\left(K_{\mathrm{a}}\right)$ for collagen.

\section{RESULTS}

\section{Specific binding of CbpA to collagens}

CbpA was previously found to mediate binding of $A$. pyogenes to collagen (Deivanayagam et al., 2000). To analyse the specificity of interactions of CbpA with collagen, we immobilized a number of ECM or plasma proteins onto microtitre wells and then incubated the plates with recombinant full-length CbpA or region A of CbpA. Binding of recombinant CbpAs to immobilized proteins was detected by addition of an anti-CbpA antibody to the wells. In confirmation of previous data, CbpA proteins bound to type I collagen but not to other ligands such as laminin, elastin, ovalbumin or albumin (Fig. 1a). Interestingly, CbpA and its A domain were found to interact also with fibronectin and to a lesser extent with fibrinogen. The ability of CbpA to bind both collagen and fibronectin appeared to be a peculiar property of $\mathrm{CbpA}$, because other bacterial collagen-binding proteins such as CNA from Staph. aureus and ACE from Ent. faecalis did not bind to fibronectin (data not shown). With exclusion of collagen V and IX, for which CbpA showed reduced binding, the binding of $\mathrm{CbpA}$ to genetically distinct collagen types was very similar (Fig. 1b).

To further demonstrate the specific interaction of CbpA with collagen, a competitive binding assay was set up in which CbpA was pre-incubated with soluble type I collagen or the proteins fibronectin, fibrinogen and ovalbumin, and then tested for binding to surface-coated type I collagen. Pre-incubation of CbpA with increasing amounts of soluble collagen resulted in inhibition of the protein binding to immobilized collagen by $80 \%$ at the highest concentration of soluble competitor, while a negligible effect was detected when CbpA was pre-incubated with fibronectin, fibrinogen or ovalbumin (Fig. 1c).

\section{Saturable binding of CbpA to collagens and CB peptides}

To provide further evidence that CbpA was a relevant partner for binding to collagen, microtitre wells coated with type I collagen were incubated with increasing amounts of CbpA or region A of CbpA. As shown in Fig. 2, full-length CbpA and region A bound to collagens in a dose-dependent fashion, whereas the binding to the wells coated with albumin was minimal (data not shown). From these assays we estimated the $K_{\mathrm{D}}$ value of full-length CbpA and region A for type I collagen as 5.26 and $1.12 \mathrm{nM}$, respectively (Table 1). $K_{\mathrm{D}}$ values in the same range were obtained by incubating increasing concentrations of CbpA or region $\mathrm{A}$ of $\mathrm{CbpA}$ with surface-coated type II collagen (Table 1).

The full-length CbpA and region A contain 20 and 4 tryptophan residues, respectively, whereas no tryptophan residues are present in the triple helix of type I or II collagen. The fluorescence spectra of $\mathrm{CbpA}$ and of region $\mathrm{A}$ showed fluorescence emission maxima at 340 and $350 \mathrm{~nm}$, respectively; the difference in quantum yield for region $\mathrm{A}$ is presumably caused by the lower number of tryptophan residues (data not shown).

Preliminary analysis indicated that the binding of type I or II collagen to CbpA resulted in quenching of intrinsic 


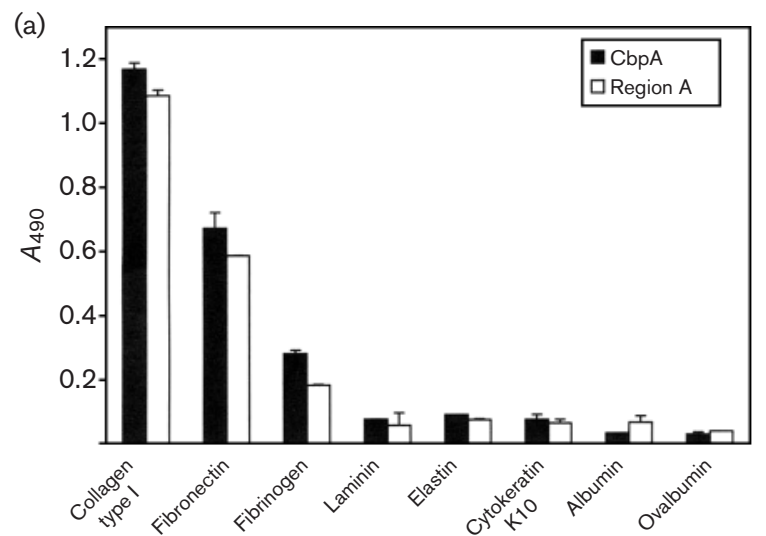

(b)
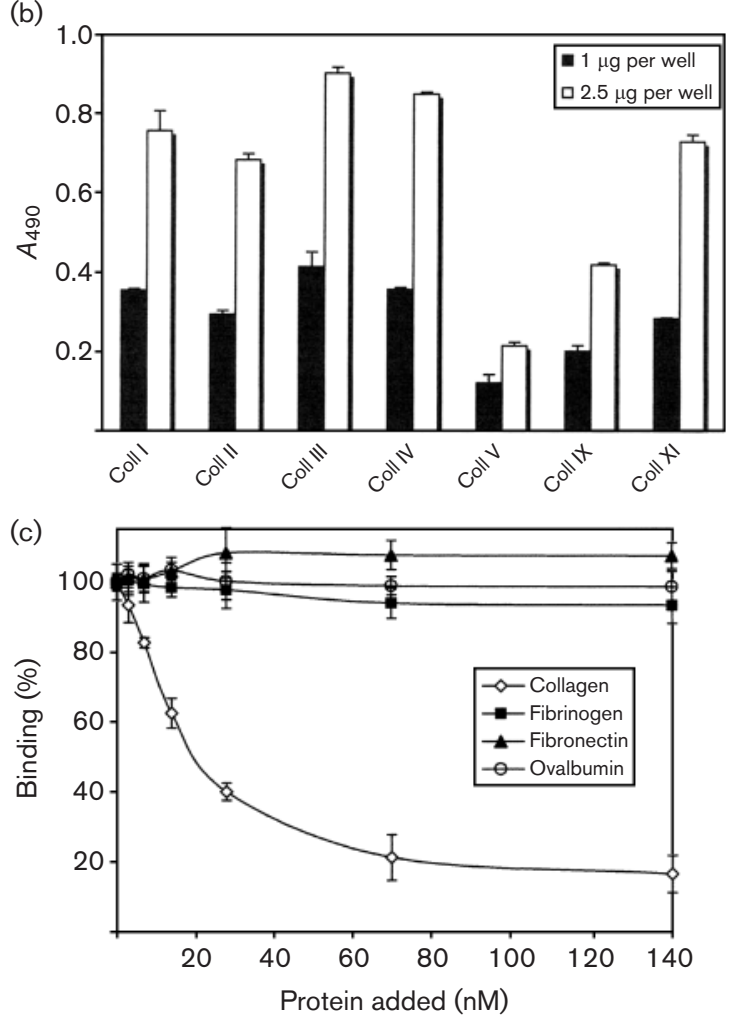

Fig. 1. (a) CbpA specifically binds to collagens: CbpA binding to surface-coated type I collagen and extracellular or plasma proteins. The indicated proteins $(1 \mu \mathrm{g})$ were immobilized overnight onto microtitre wells. Plates were incubated with $1 \mu \mathrm{g}$ full-length $\mathrm{CbpA}$ or region $\mathrm{A}$ of $\mathrm{CbpA}$ for $60 \mathrm{~min}$ at $22^{\circ} \mathrm{C}$, and after washing, $50 \mathrm{ng}$ mouse anti-CbpA lgG was added for 90 min. Antibody binding was determined by incubating the wells with $1: 1000$ dilution of a peroxidase-conjugated rabbit anti-mouse antibody. (b) Binding of $\mathrm{CbpA}$ to different collagen types. Microtitre wells coated with $1 \mu \mathrm{g}$ of the indicated collagens were incubated with $1 \mu \mathrm{g}$ CbpA for $60 \mathrm{~min}$. The binding of $\mathrm{CbpA}$ to the immobilized substrate was detected as reported above. (c) Dose-dependent effect of soluble type I collagen, fibronectin, fibrinogen and ovalbumin on the binding of CbpA to immobilized type I collagen. Binding of $\mathrm{CbpA}$ to collagen was detected as reported in (a). Data are expressed as a percentage of $\mathrm{CbpA}$ binding in the absence of competitors. Values represent the means \pm SD of triplicate wells.

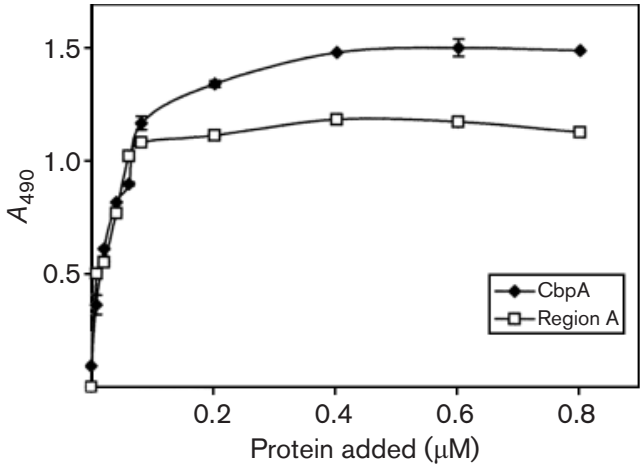

Fig. 2. CbpA binds type I collagen in a dose-dependent and saturable manner. Microtitre wells were coated with $1 \mu \mathrm{g}$ collagen I and then analysed for the binding of increasing amounts of fulllength $\mathrm{CbpA}$ or region $\mathrm{A}$ of $\mathrm{CbpA}$. Binding of the ligand was detected as reported in Fig. 1(a). Values represent the means $\pm S D$ (error bars not shown where smaller than symbols) of triplicate wells. This experiment was repeated three times with similar results.

tryptophan fluorescence (ITF). We therefore measured the fluorescence of $\mathrm{CbpA}$ in the presence of increasing concentrations of collagen I or II when the protein was excited at $295 \mathrm{~nm}$ (Fig. 3a, b). Collagens quenched the intrinsic fluorescence of $\mathrm{CbpA}$ in a dose-dependent manner, whereas no quenching of fluorescence emission was detected when only PBS or non-collagenous proteins were added to the mixtures of the recombinant proteins. Analysis of the tryptophan quenching data by a modified Stern-Volmer plot gave $K_{\mathrm{D}}$ values of 2.23 and $1.0 \mathrm{nM}$, respectively, for collagens I and II (Fig. 3a, b, Table 1). Affinities of region A for type I and II collagens as measured by ITF were 2.27 and $6.86 \mathrm{nM}$, respectively (Table 1 ).

To identify CbpA binding sites in collagen, we examined the binding of CbpA to fragments of type I or II collagen generated by cyanogen bromide cleavage (CB peptides). CbpA bound almost all the fragments tested (Fig. 4) although a preferential binding of $\mathrm{CbpA}$ to the peptides CB3.8(I), CB7(I), CB8(I) and CB11(II) was observed. However, it remains to be determined whether the better recognition of these peptides by $\mathrm{CbpA}$ reflects the interaction with specific binding sites or is the result of a differential coating efficiency when peptides of different size are tested.

Saturation kinetics of $\mathrm{CbpA}$ or region $\mathrm{A}$ of $\mathrm{CbpA}$ for $\mathrm{CB}$ peptides CB3,8(I), CB8(I) and CB11(II) determined either by solid-phase binding assay or by ITF measurements gave $K_{\mathrm{D}}$ values in the range of 1-16 $\mathrm{nM}$ (Table 1).

\section{Anti-CbpA antibodies block interaction of CbpA with collagen}

Purified IgG antibodies isolated from an antiserum raised against full-length CbpA were tested for their ability to 
Table 1. $K_{\mathrm{D}}$ values $(\mathrm{nM})$ of $\mathrm{CbpA}$ protein for collagen and $\mathrm{CB}$ peptides

\begin{tabular}{|c|c|c|c|c|c|c|c|c|c|c|}
\hline & \multicolumn{2}{|c|}{ Collagen type I } & \multicolumn{2}{|c|}{ Collagen type II } & \multicolumn{2}{|c|}{ CB3.8 (I) } & \multicolumn{2}{|c|}{ CB8 (I) } & \multicolumn{2}{|c|}{ CB11 (II) } \\
\hline & ELISA & ITF & ELISA & ITF & ELISA & ITF & ELISA & ITF & ELISA & ITF \\
\hline CbpA & 5.26 & 2.23 & 15 & 1.0 & 14 & 1.64 & 14.2 & 1.07 & 16 & 1.66 \\
\hline A domain & 1.12 & 2.27 & 3.73 & 6.86 & 6.25 & 3.14 & 7.57 & 5.22 & 8 & 3.33 \\
\hline
\end{tabular}

inhibit CbpA-dependent A. pyogenes adherence to a collagen substrate. Anti-CbpA IgG was a potent inhibitor of cell adhesion, causing $85 \%$ inhibition at $10 \mu \mathrm{g} \mathrm{ml}$
(Fig. 5). A similar blocking effect was obtained when collagen-coated wells were incubated with biotin-labelled $\mathrm{CbpA}$ in the presence of increasing concentrations of the (a)

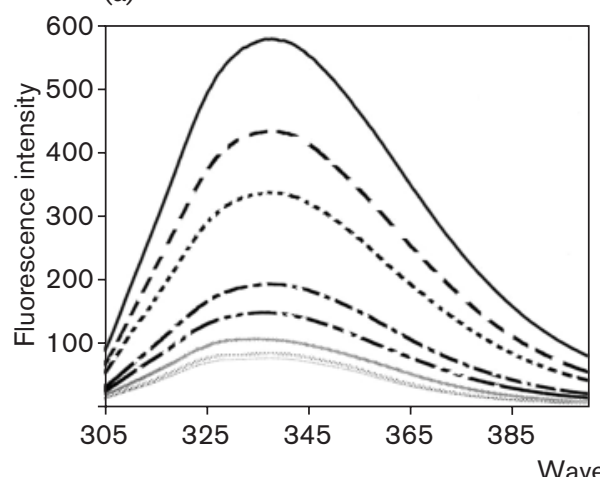

(b)
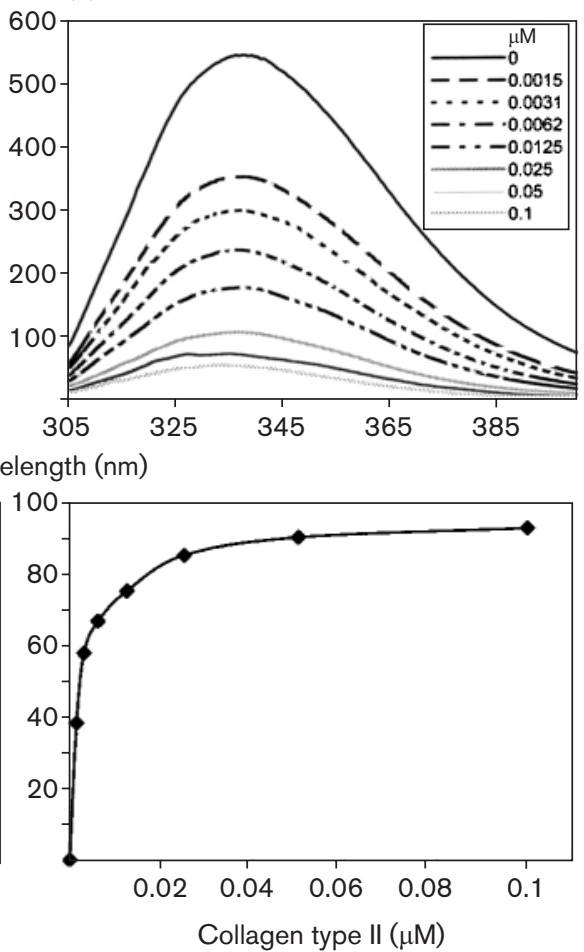
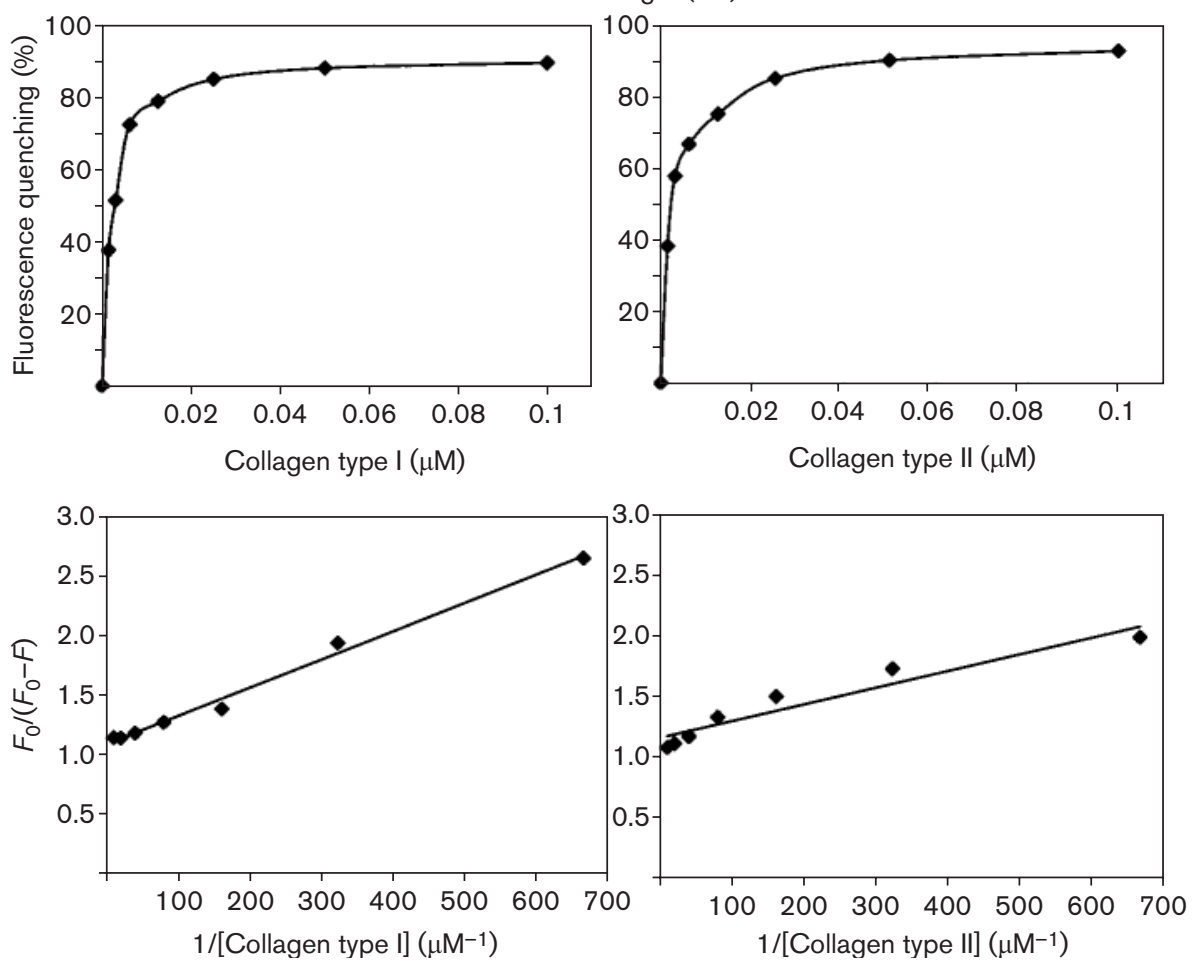

Fig. 3. Analysis of CbpA binding to type I (a) and type II (b) collagens by fluorescence quenching. Top panels, tryptophan fluorescence emission spectra of full-length $\mathrm{CbpA}$ in the absence or presence of increasing amounts of type I or II collagen. No quenching was observed when $\mathrm{CbpA}$ was incubated with $\mathrm{PBS}$ or non-collagenous proteins. Middle panels, quenching of $\mathrm{CbpA}$ intrinsic fluorescence in the presence of increasing concentrations of collagen. The intrinsic fluorescence of CbpA in the absence of collagen was set as the relative fluorescence intensity equal to 100. Bottom panels, modified Stern-Volmer plots of the data acquired from the fluorescence quenching assay. 


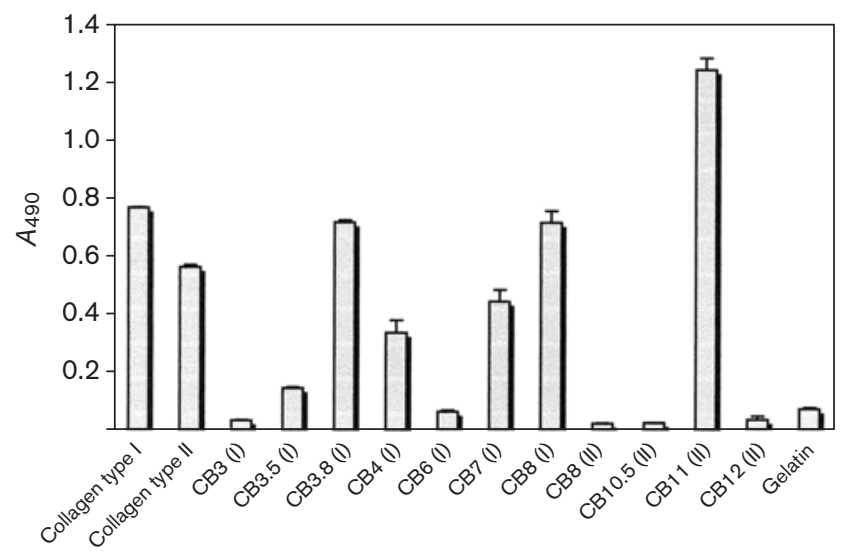

Fig. 4. Binding of $\mathrm{CbpA}$ to $\mathrm{CB}$ peptides. Microtitre wells coated with $1 \mu \mathrm{g}$ of the indicated CB peptides were incubated with $1 \mu \mathrm{g}$ $\mathrm{CbpA}$ for $60 \mathrm{~min}$. The binding of $\mathrm{CbpA}$ to the immobilized substrate was detected as reported in Fig. 1(a). The data are means \pm SD of triplicate samples.

same antibody (data not shown). Conversely, no effect was detected when either bacteria or the recombinant $\mathrm{CbpA}$ were incubated with immobilized collagen in the presence of IgG isolated from a pre-immune serum.

\section{Immunological cross-reactivity of antibodies against collagen-binding proteins from different bacterial species}

CbpA, CNA from Staph. aureus, ACE from Ent. faecalis and Acm from Ent. faecium are collagen-binding proteins exhibiting significant residue similarity (Esmay et al., 2003). Thus, it was of interest to analyse the possible immunological cross-reactivity of these adhesins. To this end, CbpA was investigated in ELISA format for the reactivity with $\mathrm{mAbs}$ against the $\mathrm{N} 2$ module of region $\mathrm{A}$ of CNA (CNA19) (Visai et al., 2000) or ACE40, which are recombinant segments encompassing the collagen-binding site in these two adhesins (Patti et al., 1993; Rich et al., 1999). mAbs against CNA strongly reacted with the immobilized CNA19 fragment, but did not recognize immobilized CbpA to any degree (data not shown). The collection of mAbs raised against ACE40 reacted well with homologous antigen, and a number of mAbs (3E11, 8A1, 9D4, 10E4, 11A6, 11C7, 11D12 and 12A2) also recognized CbpA (Fig. 6a). However, the relative affinity of these antibodies for CbpA epitopes was reduced $\sim 100$-fold compared to that for ACE homologous epitopes $\left(K_{\mathrm{D}}\right.$ values of $100 \mathrm{nM}$ vs $1 \mathrm{nM}$, respectively). To analyse whether similar cross-reactivity would be observed under more physiological conditions, the panels of mAbs against CNA and ACE were examined for reactivity with adhesins directly expressed on the surface of bacteria. Consistent with the poor cross-reactivity of the anti-CNA monoclonal antibodies with recombinant $\mathrm{CbpA}$, the mAbs against CNA

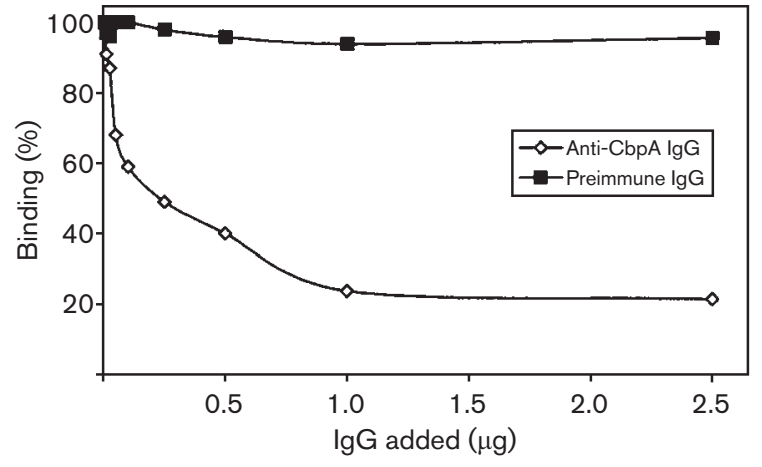

Fig. 5. Antibodies against $\mathrm{CbpA}$ block the interaction of $\mathrm{CbpA}$ with collagen. Surface-coated collagen type I was incubated for $90 \mathrm{~min}$ at $37{ }^{\circ} \mathrm{C}$ with $5 \times 10^{7}$ cells of $A$. pyogenes in the presence of increasing concentrations of mouse anti-CbpA IgG. After extensive washing, collagen-bound bacteria were incubated with $1 \mu \mathrm{g}$ of a rabbit anti- $A$. pyogenes IgG. Binding of antibody to bacteria was detected by addition of a peroxidase-labelled goat anti-rabbit secondary antibody. The values are expressed as percentages of the control lacking inhibitor. The effect of preimmune IgG on adherence of bacteria to collagen is shown as a control. Bars represent SD from the means of triplicate determinations.

did not show any reactivity towards CbpA expressed on the surface of $A$. pyogenes (data not shown). Conversely, an even wider reactivity was noticed following incubation of the panel of anti-ACE mAbs with immobilized cells of $A$. pyogenes, indicating a more favourable display of the epitopes when CbpA was presented on the bacterial cell surface (Fig. 6b). Similar results were obtained when CbpA or A. pyogenes cells were reacted with polyclonal antibodies against CNA or ACE40. A lack of cross-reactivity was observed when recombinant CbpA or A. pyogenes cells were incubated with polyclonal antibodies against Acm (data not shown).

\section{Spectroscopic characterization of CbpA}

The calculated molecular masses (from the primary amino acid sequence) of the full-length $\mathrm{CbpA}$ and region $\mathrm{A}$ were $121.9 \mathrm{kDa}$ and $35.8 \mathrm{kDa}$, respectively. $\mathrm{CbpA}$ and region $\mathrm{A}$ eluted from a size-exclusion chromatography column (Superose $12 \mathrm{HR} 10 / 30$ ) at a position equivalent to $163 \mathrm{kDa}$ and $24 \mathrm{kDa}$, respectively (data not shown). This result suggests that full-length $\mathrm{CbpA}$ may adopt an extended conformation, whereas region A appears smaller than expected and more compact.

The spectral properties of full-length $\mathrm{CbpA}$ and of region $\mathrm{A}$ were investigated by CD. Far-UV CD spectra of the fulllength CbpA and the A domain showed a single maximum and minimum at 200 and $215-220 \mathrm{~nm}$, respectively (Fig. 7a). Deconvolution of the CD spectra by using three independent procedures showed that the proteins are 


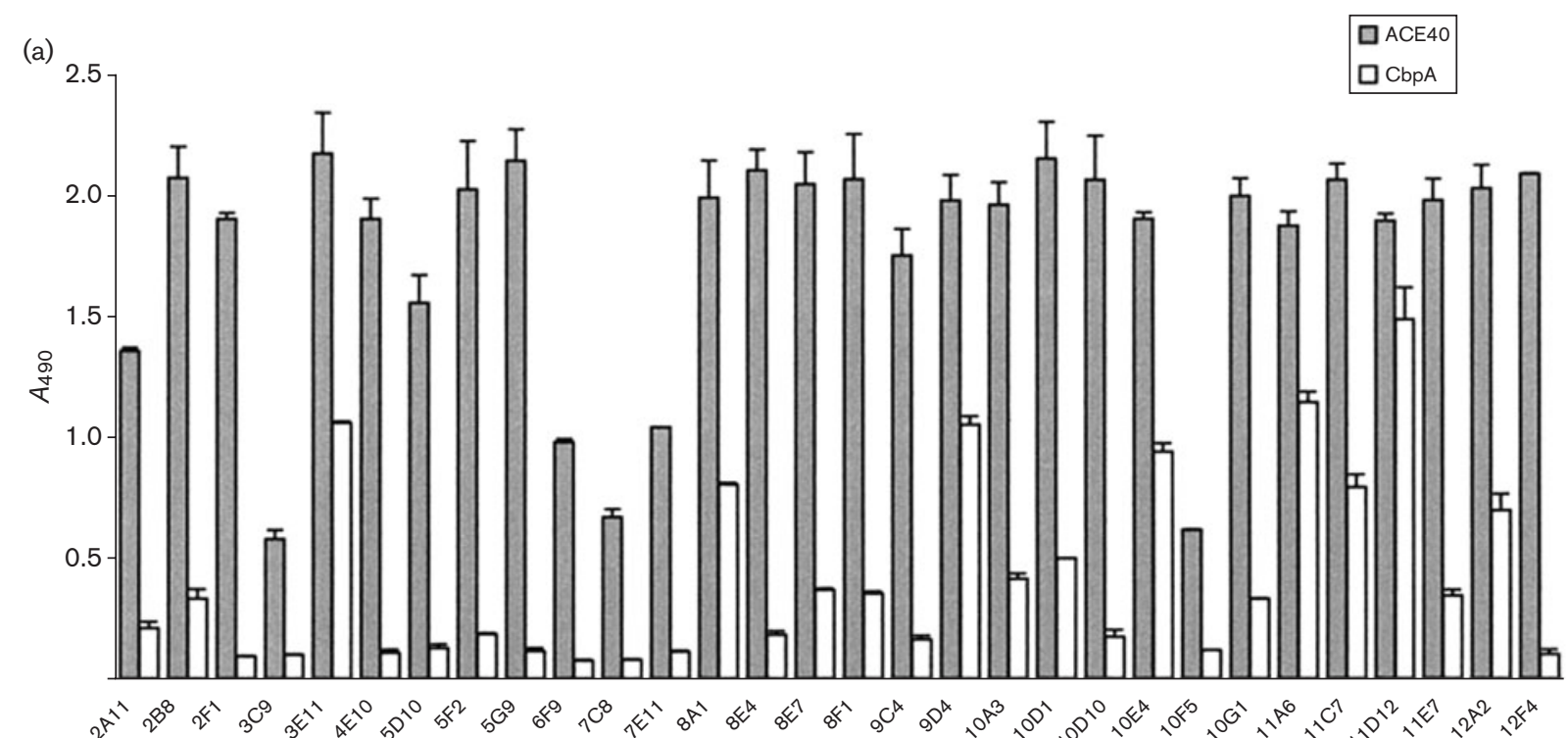

Anti-ACE40 mAb added

(b)

$$
\begin{aligned}
& \text { (b) } \\
& \\
& \text { 웜 }
\end{aligned}
$$

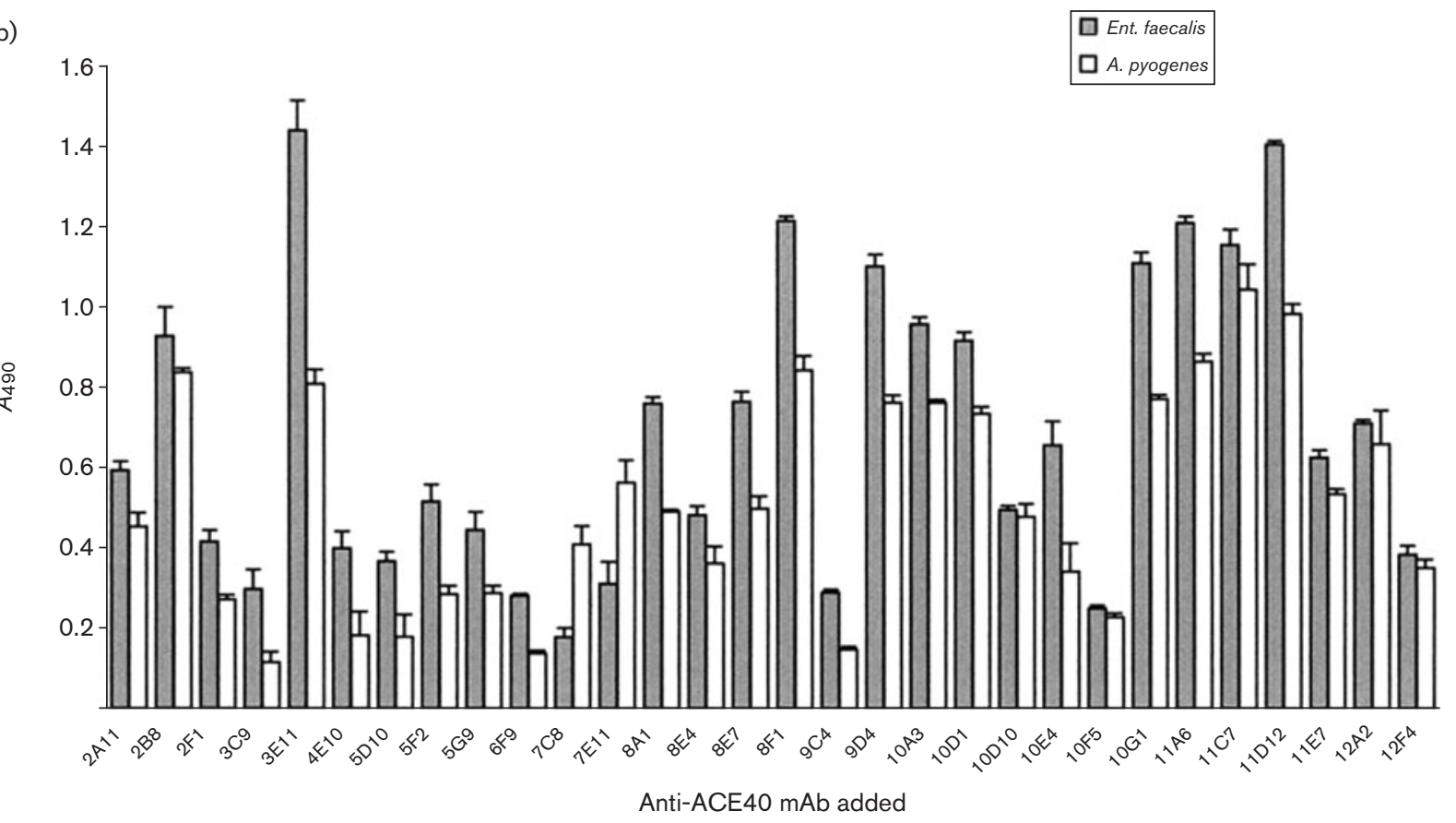

Fig. 6. Immunological cross-reactivity of recombinant collagen-binding proteins $\mathrm{CbpA}$ and ACE. (a) Collagen-binding proteins CbpA and ACE40 (each $1 \mu \mathrm{g}$ ) were immobilized onto microtitre wells. Plates were incubated with $1 \mu \mathrm{g}$ mouse monoclonal antibodies against ACE40 and bound antibody detected by addition of a peroxidase-conjugated rabbit anti-mouse antibody. (b) A. pyogenes BBR1 or Ent. faecalis $706897\left(5 \times 10^{7}\right.$ cells each) immobilized onto microtitre wells were incubated with $1 \mu \mathrm{g}$ mAbs against ACE40. Binding of antibody to cells was detected as described for Fig. 1(a). Data are means $\pm S D$ of triplicate wells.

mainly composed of $\beta$-sheets and indicated the relative content of secondary structure elements of both the proteins (Table 2). The near-UV CD spectra of CbpA and of region $\mathrm{A}$ indicated that both proteins are folded into a compact tertiary structure (Fig. $7 \mathrm{~b}$ ) and the differences in dichroic activity for region A may be due to the lower number of aromatic residues. All the aromatic residues contribute to the near-UV CD spectra of $\mathrm{CbpA}$ and region A: signals around the region $260-270 \mathrm{~nm}$ are attributable to phenyalanine residues, signals from 275 to $288 \mathrm{~nm}$ are attributable to tyrosine and those from 290 to $300 \mathrm{~nm}$ to tryptophan. The near-UV CD spectrum of CbpA exhibited 

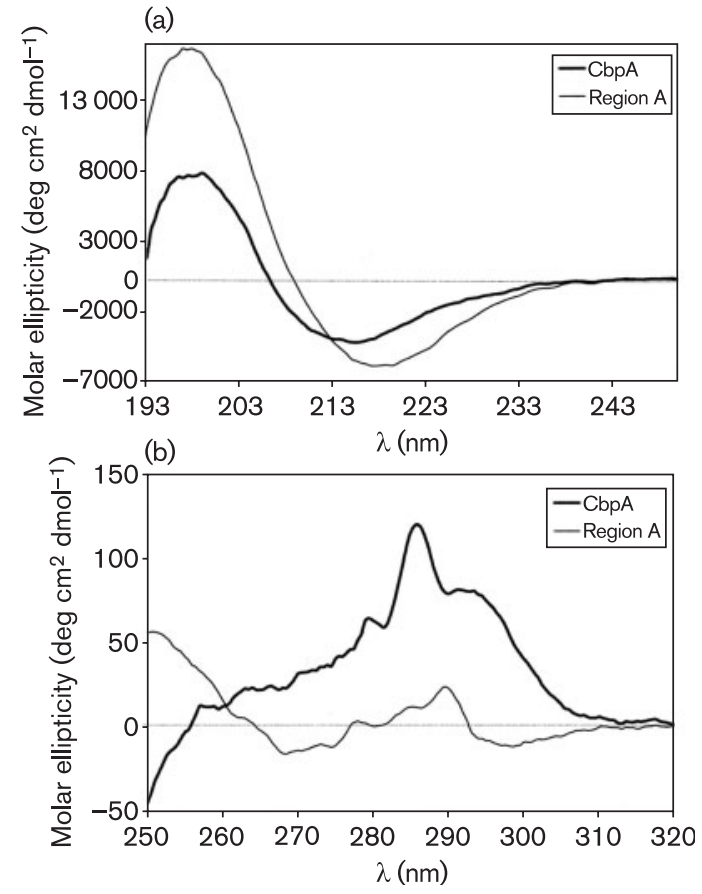

Fig. 7. Spectroscopic analysis of CbpA. Far-UV CD (a) and nearUV CD (b) spectra of CbpA and region $A$ were recorded at $20{ }^{\circ} \mathrm{C}$ in $20 \mathrm{mM}$ phosphate buffer at $\mathrm{pH}$ 7.0. Far-UV CD spectra were recorded at $0.1 \mathrm{mg} \mathrm{ml}^{-1}$ protein concentration. The predicted secondary structure composition of each protein is reported in Table 2. Near-UV CD spectra were recorded in a $1 \mathrm{~cm}$ quartz cuvette at 0.90 and at $1.28 \mathrm{mg} \mathrm{ml}^{-1}$ protein concentration for CbpA and region $A$, respectively. The reported spectra are the average of five scans, corrected for buffer blank, and were smoothed.

maxima at 278, 285, 290 and $294 \mathrm{~nm}$. The near-UV CD spectrum of region A showed a positive band in the tryptophan region but differed at shorter wavelengths from those of full-length CbpA. In conclusion, the spectral profiles of both the proteins suggested that they have a well-defined tertiary structure and that all the aromatic residues are locked into tertiary contacts.

\section{DISCUSSION}

A family of structurally related collagen-binding proteins is found on Gram-positive bacteria: among them are CNA from Staph. aureus (Patti et al., 1992), ACE from Ent. faecalis (Nallapareddy et al., 2000) and Acm from Ent. faecium (Nallapareddy et al., 2003). We previously identified the first A. pyogenes MSCRAMM, CbpA, which is capable of binding type I collagen (Esmay et al., 2003). In this study we further examined the binding properties of CbpA to collagens, compared the immunological crossreactivity of $\mathrm{CbpA}$ with other bacterial collagen-binding adhesins and analysed some of the structural aspects of the protein. First, we demonstrated that $\mathrm{CbpA}$ and the $\mathrm{A}$ region of CbpA bind to type I and II collagen specifically, saturably and with similar affinities. The apparent $K_{\mathrm{D}}$ values of the interaction between type I or II collagen and CbpA proteins are in the range of $1-15 \mathrm{nM}$, as determined by ELISA and ITF; these values are lower than those observed for the collagen-binding proteins rBA0871A and rBA5258A from Bacillus anthracis (Xu et al., 2004b) and ACE from Ent. faecalis (Rich et al., 1999).

An interesting question is whether $\mathrm{CbpA}$ behaves promiscuously in its binding to different collagen types. Our data indicate that this is the case. In fact, $\mathrm{CbpA}$ recognizes almost all the collagen types tested. This feature could broaden the spectrum of potential $A$. pyogenes infection sites and make this bacterium less dependent on local variation in tissue composition and availability of specific components, which is consistent with the ability of this organism to infect a variety of host species and tissue types (Jost \& Billington, 2005). In addition, CbpA binds a number of peptides generated by $\mathrm{CNBr}$ cleavage of type I and II collagens.

The binding of CbpA to different CB peptides is consistent with the presence of highly repetitive sequences in the collagen $\alpha$-chains. This suggests that the CbpA binding sites are scattered over the collagen molecule and that CbpA can bind many sites along the collagen molecule. In addition, on the basis of the tendency of $\mathrm{CB}$ peptides to form homologous homotrimers (Rossi et al., 1996) and the similar affinity of CbpA for both collagens and CB peptides we can speculate that collagen triple helix is the recognition element for CbpA binding. Recently, several bacterial surface proteins that were regarded as binding a single ligand were shown to bind additional host proteins. For example, the fibronectin-binding proteins FnbpA and FnbpB from Staph. aureus also recognize fibrinogen and elastin (Roche et al., 2004), while ClfB, originally described as a fibrinogen-binding staphylococcal receptor, binds to

Table 2. Summary of secondary structural components in CbpA protein

Values reported here are an average of results obtained using the CONTIN, CDSSTR and SELCON3 deconvolution programs.

\begin{tabular}{|lcccc|}
\hline & $\boldsymbol{\alpha}$-Helix & $\boldsymbol{\beta}$-Sheet & Turns & Random \\
\hline CbpA & $0.042 \pm 0.03$ & $0.373 \pm 0.05$ & $0.229 \pm 0.032$ & $0.323 \pm 0.007$ \\
A domain & $0.044 \pm 0.014$ & $0.42 \pm 0.009$ & $0.216 \pm 0.008$ & $0.316 \pm 0.017$ \\
\hline
\end{tabular}


cytokeratin 10 (Walsh et al., 2004). In line with this, here we show a second binding activity for CbpA. Both recombinant full-length $\mathrm{CbpA}$ and the A region of $\mathrm{CbpA}$ bind fibronectin. In addition, we tested the competitive effect of type I collagen on CbpA binding to surface-coated fibronectin or, conversely, the potential interference of soluble fibronectin on the binding of CbpA to immobilized type I collagen in ELISA assays. In these conditions collagen did not affect CbpA binding to fibronectin, nor did fibronectin influence $\mathrm{CbpA}$ binding to collagen (data not shown and Fig. 1c). These findings rule out the possibility that binding of CbpA to either ligand could be attributed to an artefact of collagen or fibronectin contamination. Moreover, the absence of cross-inhibition by one ligand on the binding of the other one to CbpA clearly indicates that collagen and fibronectin recognize different subsites of CbpA

Vaccination of animals with a recombinant form of CNA or RspA, the collagen adhesins of Staph. aureus and Erysipelothrix rhusiopathiae, was shown to protect against challenge by wild-type Staph. aureus (Nilsson et al., 1998) and E. rhusiopathiae (Shimoji et al., 2003), respectively. The finding that CbpA is a good immunogen and that antibodies against CbpA inhibit A. pyogenes attachment to immobilized collagen suggests that CbpA might be a vaccine candidate for combating infections by this bacterium.

It has been shown that region A of CbpA exhibits similarity with A regions of other collagen-binding proteins, with the most similarity to the A region of CNA (percentage sequence identity and similarity $28 \%$ and $68 \%$, respectively). Surprisingly, we found that the immunological cross-reactivity between CbpA and CNA is very limited, as suggested by the weak recognition by the panel of mAbs against CNA of either isolated, recombinant or A. pyogenes surface-exposed CbpA. In contrast, in spite of the relatively lower sequence similarity betweeen the A domains of CbpA and ACE (24\% identity, $54 \%$ similarity), a number of anti-ACE monoclonal antibodies recognize $\mathrm{CbpA}$ in an ELISA. However, the affinity of these anti-ACE mAbs is 100 -fold lower than that for the homologous epitopes. An even wider response is observed by incubating $A$. pyogenes cells with anti-ACE mAbs, indicating that some epitopes that are exposed on the bacterial surface are more accessible than the corresponding ones present in the recombinant protein immobilized onto microtitre wells.

It has been shown that a recombinant form of A region of CNA (Zong et al., 2005) or ACE (Rich et al., 1999) has a $\beta$ sheet structure that folds into an Ig-like fold. Our CD analysis indicates that $\mathrm{CbpA}$ and the $\mathrm{A}$ region of $\mathrm{CbpA}$ are composed primarily of $\beta$-sheet structures. For this reason and on the basis of the analysis of the three-dimensional structure of A region by homology modelling (data not shown), it is plausible that the CbpA folds similarly to ACE and CNA and adopts an Ig-like fold. In addition, the finding that full-length CbpA and its A region have a substantially similar percentage of $\beta$-sheet structure suggests that, consistent with the structure of the repetitive units of CNA (Deivanayagam et al., 2000), the B domains of $\mathrm{CbpA}$ might have a $\beta$-sheet arrangement.

Earlier studies indicated that the B domains of CNA neither bind collagen nor influence the A region's collagenbinding activity (Rich et al., 1998). These B region repeat units have been proposed to serve as a stalk that projects the A region away from the staphylococcal cell surface and positions it for binding to collagen. Thus, it is reasonable to suppose that the B domain in CbpA has a similar function. In conclusion, as previously reported for CNA and ACE, CbpA is composed primarily of $\beta$-sheet structures, with a minor $\alpha$-helical component, but the global arrangement of such secondary structural elements in this MSCRAMM remains to be determined.

\section{ACKNOWLEDGEMENTS}

This work was supported by grants from the MIUR (Ministero dell'Istruzione, dell'Università e della Ricerca, Italy) (Cofin 2004) through FIRB (Fondo per gli Investimenti della Ricerca di Base, project number RBAU014T43) and FAR 2005 (Fondo d'Ateneo per la Ricerca, University of Pavia) to P.S. We thank Professor Valerio Consalvi, University of Rome 'La Sapienza' for invaluable help with spectroscopy and for critical reading the manuscript. The Centro Grandi Strumenti of the University of Pavia is also ackowledged for access to the spectroscopic equipment.

\section{REFERENCES}

Antikainen, J., Anton, L., Sillanpää, J. \& Korhonen, T. K. (2002). Domains in the S-layer protein CbsA of Lactobacillus crispatus involved in adherence to collagens, laminin and lipoteichoic acids and in self-assembly. Mol Microbiol 46, 381-394.

Billington, S. J., Jost, B. H., Cuevas, W. A., Bright, K. R. \& Songer, J. G. (1997). The Arcanobacterium (Actinomyces) pyogenes hemolysin, pyolysin, is a novel member of the thiol-activated cytolysin family. $J$ Bacteriol 179, 6100-6106.

Deivanayagam, C. C., Rich, R. R., Carson, M., Owens, R. T., Danthuluri, S., Bice, T., Höök, M. \& Narayana, S. V. (2000). Novel fold and assembly of the repetitive B region of the Staphylococcus aureus collagen-binding surface protein. Structure 8, 67-78.

Dinkla, K., Rohde, M., Jansen, W. T., Kaplan, E. L., Chhatwal, G. S. \& Talay, S. R. (2003). Rheumatic-fever associated Streptococcus pyogenes isolates aggregate collagen. J Clin Invest 111, 1905-1912.

Eftink, M. R. \& Ghiron, C. A. (1981). Fluorescence quenching studies with proteins. Anal Biochem 114, 199-227.

Esmay, P. A., Billington, S. J., Link, M. A., Songer, J. G. \& Jost, B. H. (2003). The Arcanobacterium pyogenes collagen binding protein, CbpA, promotes adhesion to host cells. Infect Immun 71, 4368-4374.

Foster, T. J. \& Höök, M. (1998). Surface protein adhesins of Staphylococcus aureus. Trends Microbiol 6, 484-488.

Hubble, T. S., Hatton, J. F., Nallapareddy, S. R., Murray, B. E. \& Gillespie, M. J. (2003). Influence of Enterococcus faecalis proteases and the collagen-binding protein, Ace, on adhesion to dentin. Oral Microbiol Immunol 18, 121-126.

Huszar, G., Maiocco, J. \& Naftolin, F. (1980). Monitoring of collagen and collagen fragments in chromatography of protein mixtures. Anal Biochem 105, 424-429. 
Jost, B. H. \& Billington, S. J. (2005). Arcanobacterium pyogenes: molecular pathogenesis of an animal opportunist. Antonie Van Leeuwenhoek 88, 87-102.

Jost, B. H., Songer, J. G. \& Billington, S. J. (2002). Identification of a second Arcanobacterium pyogenes neuraminidase and involvement of neuraminidase activity in host cell adhesion. Infect Immun $\mathbf{7 0}$ 1106-1112.

Köhler, G. \& Milstein, C. (1975). Continuous cultures of fused cells secreting antibody of predefined specificity. Nature 256, 495-497.

Laemmli, U. K. (1970). Cleavage of structural proteins during the assembly of the head of bacteriophage T4. Nature 227, 680-685.

Nallapareddy, S. R., Qin, X., Weinstock, G. M., Höök, M. \& Murray, B. E. (2000). Enterococcus faecalis adhesin, Ace, mediates attachment to extracellular matrix proteins collagen type IV and laminin as well as collagen type I. Infect Immun 68, 5218-5224.

Nallapareddy, S. R., Weinstock, G. M. \& Murray, B. E. (2003). Clinical isolates of Enterococcus faecium exhibit strain-specific collagen binding mediated by Acm, a new member of the MSCRAMM family. Mol Microbiol 47, 1733-1747.

Nilsson, I. M., Patti, J. M., Bremell, T., Höök, M. \& Tarkowski, A. (1998). Vaccination with a recombinant fragment of collagen adhesin provides protection against Staphylococcus aureus-mediated septic death. J Clin Invest 101, 2640-2649.

Nitsche, D. P., Johansson, H. M., Frick, I.-M. \& Mörgelin, M. (2006). Streptococcal protein FOG, a novel matrix adhesin interacting with collagen I in vivo. J Biol Chem 281, 1670-1679.

Nummelin, H., Merckel, M. C., Leo, J. C., Lankinen, H., Skurnik, M. \& Goldman, A. (2004). The Yersinia adhesin Yad collagen-binding domain structure is a novel left-handed parallel $\beta$-roll. EMBO J 23, 701-711.

Patti, J. M., Jonsson, H., Guss, B., Switalski, L. M., Wiberg, K., Lindberg, M. \& Höök, M. (1992). Molecular characterization and expression of a gene encoding a Staphylococcus aureus collagen adhesin. J Biol Chem 267, 4766-4772.

Patti, J. M., Boles, J. O. \& Höök, M. (1993). Identification and biochemical characterization of the ligand binding domain of the collagen adhesin from Staphylococcus aureus. Biochemistry 32, 11428-11435.

Reese, C. A. \& Mayne, R. (1981). Minor collagens of chicken hyaline cartilage. Biochemistry 20, 5443-5448.

Rich, R. L., Demeler, B., Ashby, K., Deivanayagam, C. C., Petrich, J. W., Patti, J. M., Narayana, S. V. \& Höök, M. (1998). Domain structure of the Staphylococcus aureus collagen adhesin. Biochemistry 37, 15423-15433.
Rich, R. L., Kreikemeyer, B., Owens, R. T., LaBrenz, S., Narayana, S. V., Weinstock, G. M., Murray, B. E. \& Höök, M. (1999). Ace is a collagen-binding MSCRAMM from Enterococcus faecalis. J Biol Chem 274, 26939-26945.

Roche, F. M., Downer, R., Keane, F., Speziale, P., Park, P. W. \& Foster, T. J. (2004). The N-terminal A domain of fibronectin-binding proteins A and B promotes adhesion of Staphylococcus aureus to elastin. J Biol Chem 279, 38433-38440.

Rossi, A., Vitellaro-Zuccarello, L., Zanaboni, G., Monzani, E., Dyne, K. M., Cetta, G. \& Tenni, R. (1996). Type I collagen $\mathrm{CNBr}$ peptides: species and behavior in solution. Biochemistry 35, 6048-6057.

Schaufuss, P., Sting, R. \& Lämmler, C. (1989). Isolation and characterization of an extracellular protease of Actinomyces pyogenes. Zentralbl Bakteriol 271, 452-459.

Shimoji, Y., Ogawa, Y., Osaki, M., Kabeya, H., Maruyama, S., Mikami, T. \& Sekizaki, T. (2003). Adhesive surface proteins of Erysipelothrix rhusiopathiae bind to polystyrene, fibronectin, and type I and IV collagens. J Bacteriol 185, 2739-2748.

Visai, L., Xu, Y., Casolini, F., Rindi, S., Höök, M. \& Speziale, P. (2000). Monoclonal antibodies to CNA, a collagen-binding microbial surface component recognizing adhesive matrix molecules, detach Staphylococcus aureus from a collagen substrate. J Biol Chem 275, 39837-39845.

Vuento, M. \& Vaheri, A. (1979). Purification of fibronectin from human plasma by affinity chromatography under non-denaturing conditions. Biochem J 183, 331-337.

Walsh, E. J., O’Brien, L. M., Liang, X., Höök, M. \& Foster, T. J. (2004). Clumping factor $\mathrm{B}$, a fibrinogen-binding MSCRAMM (microbial surface components recognizing adhesive matrix molecules) adhesin of Staphylococcus aureus also binds to the tail region of type I cytokeratin 10. J Biol Chem 279, 50691-50699.

Xu, Y., Rivas, J. M., Brown, E. L., Liang, X. \& Höök, M. (2004a). Virulence potential of the staphylococcal adhesin CNA in experimental arthritis is determined by its affinity for collagen. J Infect Dis 189, 2323-2333.

Xu, Y., Liang, X., Chen, Y., Koehler, T. M. \& Höök, M. (2004b). Identification and biochemical characterization of two novel collagenbinding MSCRAMMs of Bacillus anthracis. J Biol Chem 279, 51760-51768.

Zong, Y., Xu, Y., Liang, X., Keene, D. R., Höök, A., Gurusiddappa, S., Höök, M. \& Narayana, S. V. (2005). A 'Collagen Hug' model for Staphylococcus aureus CNA binding to collagen. EMBO J 24, 4224-4236.

Edited by: P. W. O'Toole 